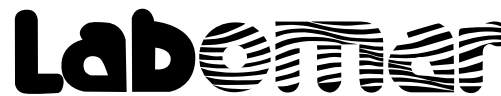

\section{Lactobacillus plantarum COMO PROBIÓTICO NO DESENVOLVIMENTO INICIAL DE JUVENIS DO ROBALO-PEVA}

\author{
Lactobacillus plantarum as a probiotic in the initial \\ development of juvenile fat snook
}

\author{
Rodrigo Matos de Souza1', Juliet Kiyoko Sugai², José Luiz Pedreira Mouriño², \\ Vinicius Ronzani Cerqueira ${ }^{4}$

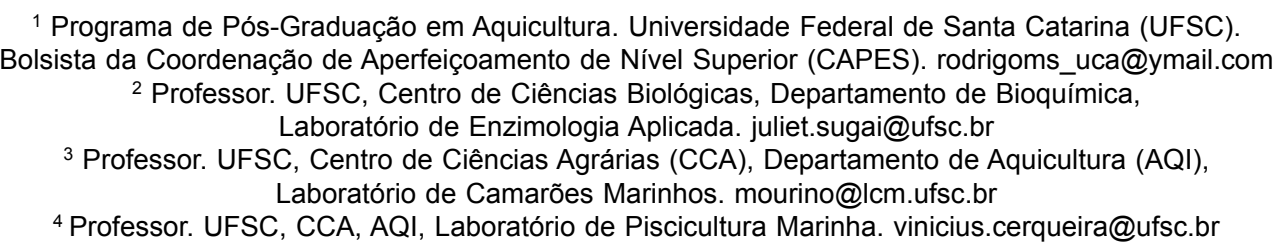

\section{RESUMO}

Com grande potencial para a aquicultura, o robalo-peva necessita de tecnologias para a produção massiva de juvenis com alta qualidade para pré-engorda. Uma forma de se obter melhores resultados com peixes saudáveis e resistentes seria a utilização de probióticos. Foi verificada a influência da suplementação de Lactobacillus plantarum à dieta de juvenis (56 dias após a eclosão) sobre o crescimento, sobrevivência, atividade de proteases digestivas e resistência ao estresse hipersalino. O ensaio de 30 dias foi constituído por três tratamentos, sendo o primeiro alimentado exclusivamente com Artemia e os dois de transição alimentar receberam por 15 dias Artemia e ração sendo um destes com suplementação de L. plantarum e, após, exclusivamente as respetivas rações. Os resultados obtidos apontam que a suplementação bacteriana durante a transição alimentar resultou no aumento da atividade de protease alcalina no trato digestório de juvenis de robalo-peva, além da maior resistência ao estresse salino, indicando peixes de melhor qualidade e mais saudáveis, auxiliando na produção massiva de juvenis de robalo peva com alta qualidade e prontos para estocagem em sistema de pré-engorda.

Palavras-chaves: Centropomus parallelus, aquicultura, enzima digestiva, bactéria, teste de estresse.

Recebido em: 2/5/2017

Aprovado em: 23/9/2017

Publicado online em: 20/1/2018 


\section{ABSTRACT}

With great potential for aquaculture, the fat snook need technologies for mass production of fingerling with high-quality for pre-ongrowing. One way of obtaining better results with healthy and resistant fish would be the use of probiotics. It was verified the influence of Lactobacillus plantarum supplementation to juvenile diet (56 days after eclosion) on growth, survival, activity of digestive proteases and resistance hypersaline stress. The test of 30 days was composed of three treatments, the first being exclusively fed with Artemia and the two feeding transition received for 15 days and Artemia feed with one of supplementation with L. plantarum and after exclusively the respective feed. The results indicate that bacterial supplementation during dietary transition resulted in increased alkaline protease activity in the digestive tract of fat snook juveniles, as well as increased resistance to salt stress, indicating fish better and healthier, assisting in production massive juvenile fat snook with high quality and ready for storage in pre-ongrowing system.

Key words: Centropomus parallelus, aquaculture, digestive enzyme, bacteria and stress test.

\section{INTRODUÇÃO}

A aquicultura vem se tornando uma atividade de grande importância para a economia mundial, resultando no aumento da contribuição na produção de alimentos, matérias-primas para uso industrial, além de organismos para repovoamentos e comércio de ornamentais (Cruz et al., 2012). Dentre todos os segmentos da aquicultura, a piscicultura marinha é o segmento com maior crescimento no mundo, entretanto, no Brasil, apesar das excelentes condições ambientais, o cultivo de peixes marinhos ainda não é uma atividade comercial consolidada (Cavalli \& Hamilton, 2009).

Um peixe com resultados promissores e com grande potencial para cultivo em águas brasileiras é o robalo-peva, Centropomus parallelus (Liebl et al., 2016; Pinho et al., 2016). Entre as características que o credenciam estão o crescimento comparável ao de muitas espécies marinhas já comercialmente cultivadas, boa taxa de conversão alimentar, capacidade de suportar diferentes salinidades e altas densidades de estocagem (Cerqueira, 2010).

Tais características têm levado ao desenvolvimento de pesquisa sobre reprodução, larvicultura e berçário, que resultou na evolução da produção de juvenis. Um fato importante observado na produção de juvenis é o baixo desempenho durante a transição do alimento vivo para o inerte (desmame) e a ausência de metodologia de cultivo após o desmame, na fase de pré-engorda, resultando em diversos estudos relacionados à alimentação visando melhorar a utilização do alimento e crescimento (Cerqueira \& Tsuzuki, 2009).

Como ingrediente funcional na nutrição de peixes, os probióticos (microrganismos que promovem o balanço gastrointestinal e que possuem numerosos benefícios, atuando no intestino com influência na atividade de enzimas digestórias, utilização do alimento, crescimento, sistema imune, resistência ao estresse e produção de peixes saudáveis) têm se tornado popular nas últimas décadas, sendo as bactérias ácido láticas (BAL) muito utilizadas (Ibrahem, 2013). Dentre estas, a utilização de Lactobacillus plantarum como probiótico vêm sendo testada em juvenis de robalo reduzindo a colonização de bactérias do tipo Vibrio sp (Souza et al., 2010) e promovendo a melhora no sistema imune (Barbosa et al., 2011). 
Desta forma, o objetivo deste estudo foi verificar se durante a transição alimentar a suplementação de L. plantarum à dieta de juvenis do robalo-peva promove crescimento em comprimento e peso, sobrevivência, aumento na atividade de proteases digestórias e na resistência ao estresse.

\section{MATERIAL E MÉTODOS}

\section{Material biológico e tratamentos experimentais}

Juvenis, com idade de 53 dias após a eclosão, provenientes de larvicultura do LAPMAR-UFSC (Alvarez-Lajonchère et al., 2004), foram estocados (5 indivíduos L-1) em tanques retangulares pretos com volume útil de $30 \mathrm{~L}$, contendo aeração moderada, temperatura de $24,4 \pm 0,8{ }^{\circ} \mathrm{C}$ mantida através de aquecedores elétricos com termostato, água de salinidade 32 com renovação de $2,5 \mathrm{~L} \mathrm{~h}^{-1}$ e fotoperíodo de $12 \mathrm{~h}$ com intensidade luminosa de 950 lux através de lâmpadas fluorescentes de $32 \mathrm{~W}$. Condições em que foram mantidos sob observação até o $56^{\circ}$ dia para início e também durante os tratamentos.

Durante 30 dias, os peixes foram submetidos a três tratamentos em delineamento inteiramente casualizado com cinco réplicas. O tratamento "Artemia": recebeu exclusivamente metanáuplios de Artemia franciscana (Salt Lake, EUA) enriquecidos com emulsão lipídica, na densidade de 37 e 50 metanáuplios $\mathrm{mL}^{-1}$, do $1 .^{\circ}$ ao $15 .^{\circ}$ dia e do $16 .^{\circ}$ ao $30 .^{\circ}$ dia do experimento, respectivamente. A eclosão dos náuplios e enriquecimento dos metanáuplios foi realizada segundo a metodologia de Hoff \& Snell (2008) e instruções do fabricante, respectivamente. Os tratamentos "dieta inerte" e dieta inerte + BAL: alimentados durante a transição alimentar $\left(1 .^{\circ}-15^{\circ}\right.$ dia) com metanáuplios de A. franciscana enriquecidos (37 $\left.m L^{-1}\right)$ em conjunto com $1-2 \mathrm{~g} \mathrm{dia}^{-1}$ de ração comercial $(200-400 \mu \mathrm{m})$ até saciedade aparente, e do $16 .^{\circ}$ ao $30 .^{\circ}$ dia exclusivamente com dieta inerte $\left(3 \mathrm{~g} \mathrm{dia}^{-1}\right)$.

No tratamento "dieta inerte + BAL" a ração foi suplementada com L. plantarum (CPQBA - 007 - 07) através da aspersão de uma cultura bacteriana na concentração de $1 x$ $10^{8} \mathrm{UFC} \mathrm{mL} \mathrm{m}^{-1}$, crescida previamente em caldo MRS, em agitação contínua a $30^{\circ} \mathrm{C}$ por $48 \mathrm{~h}$. No tratamento "dieta inerte" a ração foi aspergida com o mesmo meio líquido sem bactérias. Após a aspersão, $5 \mathrm{~kg}$ de cada ração foram mantidas em estufa a $30^{\circ} \mathrm{C}$ por $48 \mathrm{~h}$, para secagem e crescimento bacteriano, no caso da dieta suplementada, e conservadas sob refrigeração a $4^{\circ} \mathrm{C}$, durante todo o período experimental (Barbosa et al., 2011).

O alimento foi fornecido quatro vezes ao dia do $1 .^{\circ}$ ao $15 .^{\circ}$ dia $(8,11,15$ e $19 \mathrm{~h})$, e três vezes do $16 .^{\circ}$ ao $30 .^{\circ}$ dia $(8,13$ e $19 \mathrm{~h})$. As sobras de alimento e fezes foram sifonadas diariamente após a última alimentação.

A composição das rações foi determinada conforme a metodologia descrita pela Association of Official Analitycal Chemists (AOAC) em laboratório especializado. Composição proximal antes da suplementação: 57\% de proteína bruta e $14,5 \%$ de extrato etéreo. Após a aspersão do caldo MRS, que contém extrato de carne em sua composição, as rações apresentaram 57,9\% e 57,8\% de proteína bruta, e 12,7\% e 13,2\% de extrato etéreo, na ração com e sem suplementação de probiótico, respectivamente.

Foram determinados no $16 .^{\circ}$ e $30 .^{\circ}$ dias o crescimento em peso $(0,001 \mathrm{~g}$ em balança analítica), em comprimento total (mm em paquímetro) e sobrevivência, desconsiderando-se os exemplares removidos durante o experimento para a análise das atividades de proteases do trato digestório. Foram realizadas também a avaliação microbiológica, para confirmar a presença de L. plantarum na dieta suplementada e nos animais, além de um teste de estresse hipersalino no final do experimento. 
Os parâmetros de qualidade de água foram medidos semanalmente em todos os tanques: amônia (Indotest, fotocolorímetro), $\mathrm{pH}$, salinidade e oxigênio dissolvido (sonda multiparâmetro).

\section{Avaliação microbiológica}

A confirmação da colonização de L. plantarum no trato digestório e na ração, ao início e ao final do experimento, foi realizada segundo o método descrito por Souza et al. (2010) com alterações. Devido ao pequeno tamanho, a cabeça, região dorsal e caudal dos peixes foram desprezadas e somente a região visceral foi utilizada. As amostras de peixes ( 5 peixes por tratamento) e de ração ( 3 amostras de $1 \mathrm{~g}$ por tratamento) foram maceradas e homogeneizadas com solução salina estéril (1:1; p:v) e (1:5; p:v), respectivamente, submetidas a cinco diluições sucessivas (até 1:10 $)$ em solução salina e plaqueadas (100 $\mu \mathrm{L}$ da diluição final) em Ágar MRS com $2 \%$ de $\mathrm{NaCl}$ e 0,5 \% de azul de anilina como indicador. As placas foram incubadas por $48 \mathrm{~h}$ a $30^{\circ} \mathrm{C}$ em estufa. A colonização da BAL no trato digestório dos peixes foi expressa por $\mathrm{n}^{\mathrm{o}}$ de $\mathrm{UFC} \mathrm{g}^{-1}$ de trato digestório.

\section{Avaliação enzimática}

As atividades de proteases alcalina e ácida totais, foram quantificadas no sobrenadante do homogenato do trato digestório de juvenis de robalos e no sobrenadante da cultura de L. plantarum. Para a obtenção dos homogenatos, foram retirados dos peixes (5 ind. por tanque $=25$ por tratamento) a cabeça, região dorsal e caudal, sendo a região visceral com trato digestório homogeneizada com água destilada gelada, 1:6 (p: v) nas amostras dos dias $1^{\circ}$ e $16^{\circ}$, e $1: 7$ (p: v) no $30^{\circ}$ dia, utilizando um homogeneizador van Potter por 2,5 min. O homogenato foi centrifugado a $27167 \mathrm{~g}$ por $15 \mathrm{~min}$ a $3^{\circ} \mathrm{C}$. O sobrenadante foi usado para a quantificação da proteína solúvel e atividades proteolíticas (Vega-Orellana et al., 2006). Foi determinada, também, a atividade de proteases extracelulares bacteriana no sobrenadante da cultura bacteriana crescida por $48 \mathrm{~h}$. A determinação da concentração de proteína solúvel para determinação da atividade proteolítica foi feita através do método de Bradford (1976), usando albumina de soro bovino como padrão.

A atividade de protease alcalina total foi determinada pela hidrólise da Azocaseína pelo método descrito por Garcia-Carreño et al. (1997) a $25^{\circ} \mathrm{C}$. Para a determinação dos produtos desta atividade, o sistema de incubação, depois de cessada a reação, foi mantido por $15 \mathrm{~min}$ a $4^{\circ} \mathrm{C}$ e centrifugado a $11000 \mathrm{~g}$ por $5 \mathrm{~min}$. A absorbância, a $366 \mathrm{~nm}$, deste sobrenadante foi determinada em espectrofotômetro. A atividade de protease alcalina total foi expressa em atividade específica ( $\mathrm{mU} \mathrm{mg}^{-1}$ de proteína), pela diferença na absorbância entre o teste $(n=5)$ e um controle, por minuto, por $m L$ do sistema de reação (Unidade de enzima), por mg de proteína no extrato enzimático ou no sobrenadante da cultura bacteriana (= $\Delta$ abs. . $_{366 \mathrm{~nm}} \mathrm{~min}^{-1} \mathrm{~mL}^{-1} \mathrm{mg}^{-1}$ de proteína).

A atividade de protease ácida foi determinada através da hidrólise de hemoglobina bovina pelo método descrito por Anson (1938) com pequenas modificações, conforme descrito por Vega-Orellana et al. (2006). Os produtos da hidrólise ácida, solúveis ao ácido tricloroacético (TCA), presentes no sistema de incubação $\left(25^{\circ} \mathrm{C}\right)$ foram determinados pelo reagente Folin-Ciocalteau, a $660 \mathrm{~nm}$, através de uma curva padrão de tirosina. A atividade foi expressa como atividade específica ( $\mathrm{mU} \mathrm{mg}^{-1}$ de proteína): $\mu \mathrm{mol}$ de tirosina, por min, por $\mathrm{mL}$ (Unidade de enzima), por $\mathrm{mg}$ de proteína por $\mathrm{mL}$ do homogenato ou do sobrenadante da cultura bacteriana. 


\section{Teste de estresse hipersalino}

Para avaliar a qualidade fisiológica dos juvenis, após o final do período experimental, os peixes foram submetidos ao aumento na salinidade da água, segundo a metodologia descrita por Kjorsvik et al. (2003). Foram mantidos 30 peixes por tratamento em suas respetivas unidades experimentais $(n=3)$ com $6 \mathrm{~L}$ de água com salinidade de 32 e temperatura de $24^{\circ} \mathrm{C}$. Após $24 \mathrm{~h}$ em jejum, foram expostos à salinidade de 75 , obtida através da adição de $100 \mathrm{~mL}$ solução hipersalina ( $\mathrm{NaCl}$ dissolvido em água marinha) em cada unidade experimental. A mortalidade foi quantificada considerando mortos os indivíduos com perda de mobilidade e equilíbrio, mudança de coloração e ausência de resposta a estímulo (toque na cauda) a cada 10 min de exposição, até o máximo de 50 min.

\section{Análise estatística}

Os dados de sobrevivência $\left(15^{\circ}\right.$ e $30^{\circ}$ dia) e teste de estresse foram inicialmente transformados em arcsen $(\sqrt{ } x)$ e os de crescimento, qualidade de água e atividade enzimática em $\log (x+1)$. Todos os dados foram inicialmente submetidos ao teste de Kolmogorov-smirnov de distribuição normal, de Bartlett de homogeneidade de variâncias e posteriormente, atendendo aos pressupostos, à Análise de Variância com medidas repetidas no tempo (ANOVA, repetaed measures) para teste de estresse e atividade enzimática, e de 1 fator (ANOVA, one-way) para crescimento, sobrevivência e qualidade de água. Ambos com nível de significância de 5\%. A avaliação de médias foi feita através do teste de Tukey (ZAR, 1996). Os resultados foram apresentados como média \pm desvio padrão (DP).

\section{RESULTADOS}

Ao final dos 30 dias de experimento foi observada colonização de L. Plantarum somente no trato digestório dos peixes que receberam ração suplementada, enquanto que nos tratamentos sem suplementação não houve colonização. Não foi verificada diferença significativa para crescimento em peso, comprimento total e sobrevivência entre os tratamentos ao final do período amostral $(\mathrm{p}>0,05)$ (Tabela I).

Tabela I - Comprimento total, peso úmido e sobrevivência de juvenis de robalo alimentados com Artemia, dieta inerte e dieta inerte suplementada com BAL, e colonização de Lactobacillus plantarum (BAL) no trato digestório e ração.

\begin{tabular}{lcccc}
\hline & Dia & Artemia & Dieta inerte & Dieta inerte +BAL \\
\hline \multirow{2}{*}{ Comprimento (mm) } & $\mathbf{0}$ & $19,96 \pm 1,71$ & $19,96 \pm 1,71$ & $19,96 \pm 1,71$ \\
\cline { 2 - 5 } & $\mathbf{3 0}$ & $30,08 \pm 1,67 \mathrm{a}$ & $30,88 \pm 1,67 \mathrm{a}$ & $30,80 \pm 0,71 \mathrm{a}$ \\
\hline Peso úmido (mg) & $\mathbf{0}$ & $78,70 \pm 0,18$ & $78,70 \pm 0,18$ & $78,70 \pm 0,18$ \\
\hline Sobrevivência (\%) & $\mathbf{3 0}$ & $326,90 \pm 47,57 \mathrm{a}$ & $319,44 \pm 21,44 \mathrm{a}$ & $362,25 \pm 31,08 \mathrm{a}$ \\
\hline $\begin{array}{l}\text { Colonização no trato digestótio } \\
\text { (UFC g-1) }\end{array}$ & $\mathbf{3 0}$ & $94,8 \pm 2,1 \mathrm{a}$ & $96,0 \pm 3,3 \mathrm{a}$ & $99,8 \pm 0,2 \mathrm{a}$ \\
\hline \multirow{2}{*}{ Colonização na ração (UFC $\mathbf{~ g}^{-1}$ ) } & $\mathbf{0}$ & 0 & 0 & $4,01 \pm 0,55 \times 10^{8}$ \\
\cline { 2 - 5 } & $\mathbf{3 0}$ & NA & 0 & $4,15 \pm 0,49 \times 10^{8}$ \\
\hline
\end{tabular}

Valores apresentados como média \pm DP. Letras similares indicam médias sem diferença significativa entre os tratamentos (ANOVA, medidas repetidas; $\mathrm{p}>0,05$ ).

Os peixes alimentados com dieta inerte suplementada apresentaram atividade de protease alcalina significativamente superior $(\mathrm{p}<0,05)$ aos demais tratamentos somente no $30^{\circ}$ dia. Não foi observada diferença entre os tratamentos no início e no $16^{\circ}$ dia para ativi- 
dade específica de protease alcalina ou ao longo do período experimental para protease ácida $(p>0,05)$. Entretanto, foi observada diferença significativamente superior $(p<0,05)$ para protease alcalina e ácida no $1^{\circ}$ dia quando comparados ao $16^{\circ}$ e $30^{\circ}$ dias (Tabela II). Também foi observada produção enzimática no sobrenadante da cultura bacteriana, com as atividades específicas de protease alcalina e ácida extracelulares secretadas por L. plantarum de $1170 \pm 115 \mathrm{mU} \mathrm{mg}^{-1}$ de proteína e $3800 \pm 300 \mathrm{mU} \mathrm{mg}^{-1}$ de proteína, respectivamente.

Tabela II - Atividades específicas de proteases alcalina e ácida no homogenato do trato digestório dos juvenis de robalo durante o período experimental.

\begin{tabular}{ccccc}
\hline & & Artemia & Dieta inerte & Dieta inerte + BAL \\
\hline \multirow{2}{*}{$\mathbf{1}^{\mathbf{o}}$ dia } & Protease alcalina & $8,57 \pm 0,73^{\mathrm{a}}$ & $8,57 \pm 0,73^{\mathrm{a}}$ & $8,57 \pm 0,73^{\mathrm{a}}$ \\
\cline { 2 - 5 } & Protease ácida & $34,00 \pm 2,89^{\mathrm{a}}$ & $34,00 \pm 2,89^{\mathrm{a}}$ & $34,00 \pm 2,89^{\mathrm{a}}$ \\
\hline \multirow{2}{*}{$\mathbf{1 5}^{\mathbf{0}}$ dia } & Protease alcalina & $0,872 \pm 0,11^{\mathrm{b}}$ & $0,872 \pm 0,07^{\mathrm{b}}$ & $1,01 \pm 0,10^{\mathrm{b}}$ \\
\cline { 2 - 5 } & Protease ácida & $18,00 \pm 1,00^{\mathrm{b}}$ & $19,4 \pm 1,89^{\mathrm{b}}$ & $20,8 \pm 0,99^{\mathrm{b}}$ \\
\hline \multirow{2}{*}{$\mathbf{3 0}^{\circ}$ dia } & Protease alcalina & $1,06 \pm 0,17^{\mathrm{b} *}$ & $1,19 \pm 0,07^{\mathrm{b} *}$ & $1,48 \pm 0,14^{\mathrm{b} *}$ \\
\cline { 2 - 5 } & Protease ácida & $16,6 \pm 1,48^{\mathrm{b}}$ & $16,2 \pm 1,48^{\mathrm{b}}$ & $15,2 \pm 1,10^{\mathrm{b}}$ \\
\hline
\end{tabular}

Valores apresentados como média \pm DP de cinco réplicas. Letras diferentes indicam médias significativamente diferentes para um mesmo tratamento ao longo do tempo e * indica médias significativamente diferentes entre os tratamentos (ANOVA, medidas repetidas; $\mathrm{p}<0,05)$.

Aos 10 min de exposição ao estresse salino, os peixes de todos os tratamentos apresentaram aumento na secreção de muco, sendo as alterações como perda de mobilidade, equilíbrio e mudança na coloração também observadas no mesmo período somente nos tratamentos alimentados com Artemia ou com ração sem suplementação. Enquanto que no tratamento alimentado com ração suplementada estas alterações foram observadas somente aos 40 min de exposição ao estresse salino, antecedendo as ocorrências de morte.

Entre 20 e 50 min de exposição ao estressor, a suplementação de L. plantarum aumentou significativamente $(\mathrm{p}<0,05)$ a sobrevivência (ausência de resposta a estímulo) ao teste de estresse quando comparado aos demais tratamentos, com as primeiras mortalidades somente após 50 min de teste, enquanto que os demais tratamentos apresentaram mortes com 10 min de exposição. Foi observada também diferença significativa $(p<0,05)$ na sobrevivência ao teste hipersalino entre os tempos de exposição, a partir de 20 min de teste, para os tratamentos com peixes alimentados com Artemia e ração sem suplementação, diferença não observada nos peixes que receberam ração suplementada (Figura 1).

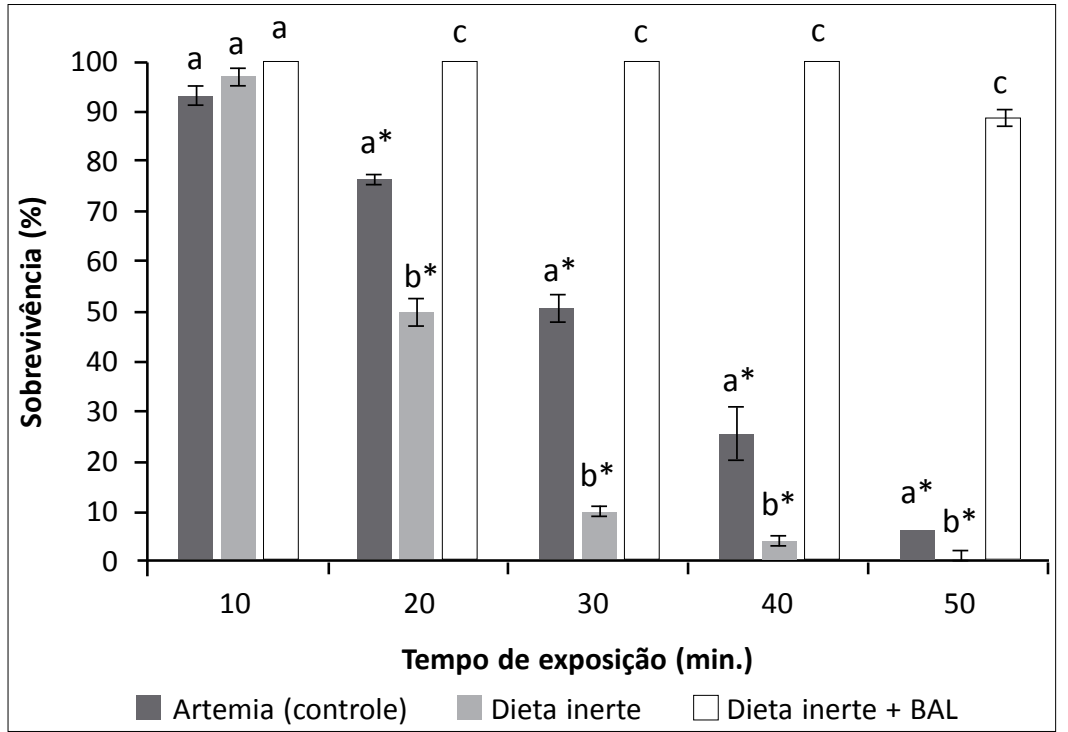

Figura 1 - Sobrevivência dos juvenis de robalo peva alimentados com Artemia, dieta inerte e dieta inerte suplementada com L. plantarum submetidos ao teste de estresse hipersalino durante um período de exposição de 10 a $50 \mathrm{~min}$. Valores apresentados como média \pm DP de três réplicas. Letras diferentes indicam médias significativamente diferentes entre os tratamentos $e^{*}$ indica diferença significativa entre os tempos de exposição nos mesmos tratamentos (ANOVA, medidas repetidas; $\mathrm{p}<0,05)$. 
$\mathrm{O}$ pH $(7,6-7,9)$, o oxigênio dissolvido de $\left(5,3-5,7 \mathrm{mg} \mathrm{L}^{-1}\right)$ e a amônia não-ionizada (não detectada) não apresentaram diferença significativa entre os tratamentos $(p>0,05)$.

\section{DISCUSSÃO}

A colonização e manutenção de L. plantarum na dieta e no trato digestório dos juvenis de robalo peva (C. Parallelus), também verificada por Souza et al., 2010 e Barbosa et al., 2011, resultou no aumento da atividade proteolítica no trato digestório dos juvenis alimentados com ração suplementada com cultura bacteriana, assim como relatado por Frouël et al. (2008), Askarian et al. (2011) e Picollo et al. (2015) em juvenis de robalo europeu (Dicentrarchus labrax) e esturjões beluga (Huso huso) e Persa (Acipenser persicus). Auxiliando, consequentemente, na digestão proteica, conversão alimentar e absorção, melhorando o processo digestório (Taoka et al., 2006; Ibrahem, 2015).

Segundo Ibrahem (2015), este aumento observado é devido à produção de enzimas extracelulares pelas bactérias aderidas ao intestino. Por outro lado, Frouël et al. (2008) atribuem a diferentes moléculas produzidas pelas bactérias este aumento nas atividades de enzimas digestórias e as alterações na estrutura intestinal, que são responsáveis pela absorção de nutrientes e secreção de enzimas proteolíticas intracelulares alcalinas (Kolkovski et al., 2009). Fato não observado na protease ácida, uma enzima digestiva estomacal, provavelmente devido à preferência de Lactobacillus sp. em colonizar o intestino (Allaeh et al. 2013).

As alterações morfométricas e na área do intestino provocadas por probióticos (Frouël et al., 2008; Mello et al., 2013) podem promover a absorção e excreção do excesso de sal no processo de hiperosmorregulação (Whithmore, 2013), inibindo os efeitos secundários do estresse como equilíbrio, mobilidade, muco e coloração, além da maior sobrevivência, promovendo melhoria nas condições de saúde e de cultivo (Rollo et al., 2006; Taoka et al., 2006; Hernandez et al., 2010).

A redução na atividade específica de protease alcalina e ácida após 15 dias de experimentos quando comparada ao início pode ser resultado do ganho de peso e o consequente aumento de proteína solúvel nos homogenatos obtidos destes juvenis, pois a expressão da atividade enzimática é uma relação entre unidade de enzima e quantidade de proteína solúvel dos homogenatos, corroborando com Cara et al. (2003) e Bolasina et al. (2006).

A similaridade no peso, comprimento total e sobrevivência entre os tratamentos também foram verificados em outros trabalhos com robalo peva (C. parallelus) (Souza et al., 2010; Barbosa et al., 2011), robalo europeu (D. labrax) (Frouël et al., 2008; Picollo et al., 2015) e robalo asiático (Lates calcarifer) (Rengpipat et al., 2008), que pode estar relacionado a duração do período experimental (Mello et al., 2013).

Os resultados obtidos apontam que a suplementação de L. plantarum na dieta durante a transição alimentar promoveu o aumento da atividade de protease alcalina no trato digestório de juvenis de robalo-peva, além da maior resistência ao estresse salino, indicando peixes de melhor qualidade e mais saudáveis. Desta forma, a aplicação de L. plantaum à dieta durante o desmame pode auxiliar na produção massiva de juvenis de robalo peva de alta qualidade e prontos para estocagem em sistema de pré-engorda.

Agradecimentos - A equipe técnica do LAPMAR, LCM, ao Dr. Elpídio Beltrame (in memoriam), Dr. Felipe N. Vieira e Dra. Mônica Y. Tsuzuki por todo auxílio no desenvolvimento deste trabalho. 


\section{REFERÊNCIAS}

Allameh, S.K.; Yusoff, F.M.; Daud, H.M.; Ringø, E.; Ideris, A. \& Saad, C.H. Characterization of a Probiotic Lactobacillus fermentum Isolated from Snakehead, Channa striatus, Stomach. JWorld Aquacult Soc, v. 44, n. 6, p. 835-844, 2013.

Alvarez-Lajonchère, L.; Cerqueira, V.R.; Silva I.D.; Araújo, J. \& Reis, M. First basis for a sustained juvenile production technology of fat snook Centropomus parallelus Poey. Hidrobiológica, v. 14, p. 37-45, 2004.

Anson, M. The estimation of pepsin, trypsin, papain and cathepsin with hemoglobin. J Gen Physiol, v. 22, p. 79-85, 1938.

Askarian, F.; Kousha, A.; Salma, W. \& Ringo, E. The effect of lactic acid bacteria administration on growth, digestive enzyme activity and gut microbiota in Persian sturgeon (Acipenser persicus) and beluga (Huso huso) fry. Aquacult Nutr, v. 17, n. 5, p. 488-497, 2011.

Barbosa, M.C.; Jatobá, A.; Vieira, F.N.; Silva, B.C.; Mouriño, J.L.P.; Andreatta, E.R.; Seiffert, W.Q. \& Cerqueira, V.R. Cultivation of Juvenile Fat Snook (Centropomus parallelus Poey, 1860) Fed Probiotic in Laboratory Conditions. Braz Arch Biol Techn, v.54, n. 4, p. 795-801, 2011.

Bolasina, S.; Pérez, A. \& Yamashita, Y. Digestive enzymes activity during ontogenetic development and effect of starvation in Japanese flounder, Paralichthys olivaceus. Aquaculture, v. 252, p. 503-515, 2006.

Bradford, M.M. A rapid and sensitive method for the quantitation of microgram quantities of protein utilizing the principle of protein - dye binding. Anal Biochem, v. 72, p. 248-254, 1976.

Cara, J.B.; Moyano, F.J.; Cárdenas, S.; Fernández-Díaz, C. \& Yúfera, M. Assessment of digestive enzyme activities during larval development of white bream. J Fish Biol, v. 63, p. 48-58, 2003.

Cavalli, R.O. \& Hamilton, S. Piscicultura marinha no Brasil com ênfase na produção do beijupirá. Rev Bras Reprod Anim, v.6, p.64-69, 2009.

Cerqueira, V.R. Cultivo de Robalo-peva (Centropomus parallelus), p. 489-520, in Baldisserotto, B. \& Gomes, L.C. (eds.), Espécies Nativas para piscicultura no Brasil. $2^{\mathrm{a}}$.ed. Editora UFSM, 608 p., Santa Maria, 2010.

Cerqueira, V.R. \& Tsuzuki, M.Y. A review of spawning induction, larviculture, and juvenile rearing of the fat snook, Centropomus parallelus. Fish Physiol Biochem, v.35, p.17-28, 2009.

Cruz, P.M.; Ibáñez, A.Ç.; Hermosillo, O.A.M. \& Saad, H.C.R. Use of Probiotics in Aquaculture. ISRN Microbiology, v. 2012, 13p. Doi:10.5402/2012/916845. 2012.

Frouël, S.; Le Bihan, E.; Serpentini, A.; Lebel, J.M.; Koueta, N. \& Nicolas, J.L. Preliminary study of the effects of commercial lactobacilli preparations on digestive metabolism of juvenile sea bass (Dicentrarchus labrax). J Mol Microbiol Biotech, v. 14, p. 100-106, 2008.

Garcia-Carreño, F.L.; Navarrete del Toro, M.A. \& Ezquerra, J.M. Digestive shrimp proteases for evaluation of protein digestibility in vitro. I. effect of protease inhibition in protein ingredients. J Mar Biotechnol, v. 5, p. 36-40, 1997. 
Hernandez, L.; Barrera, T.; Mejia, J.; Mejia, G.; Del Carmen, M.; Dosta, M.; De Lara Andrade, R. \& Sotres, J. Effects of the commercial probiotic Lactobacillus casei on the growth, protein content of skin mucus and stress resistance of juveniles of the Porthole livebearer Poecilopsis gracilis (Poecilidae). Aquacult Nutr, v. 16, p. 407-411, 2010.

Hoff, F.H. \& Snell, T.W. Plankton Culture Manual. Florida Aquafarms, Inc., 186 p., Florida, 2008.

Ibrahem, M.D. Evolution of probiotics in aquatic world: Potential effects, the current status in Egypt and recent prospectives. J Adv Res, v. 6, n.6, p. 765-791, 2013.

Kjorsvik, E.; Hoehne-Reitan, K. \& Reitan, K.I. Egg and larval quality criteria as predictive measures for juvenile production in turbot (Scophthalmus maximus L.). Aquaculture, v. 227, p. 9-20, 2003.

Kolkovsi, S.; Lazo, J. \& Izquierdo, M. Fish larvae nutrition and diet: new developments, p. 313360, in Burnel, G. \& Allan, G. (eds.), New technologies in aquaculture:Improving production efficiency, quality and enviromental management. Wood Head Publishing, 1192 p., Cambridge, 2009.

Liebl, F.; Amaral Jr, H.; Garcia, S.; Souto, L.I.M.; Carvalho, C.V.A. \& Cerqueira, V.R. Desempenho de juvenis de robalo-flecha e robalo-peva submetidos a diferentes densidades de estocagem em água doce. Bol. Inst. Pesca, v. 42, n.1, p. 145-155, 2016.

Mello, H.; Moraes, J.R.E.; Niza, I.G.; Moraes, F.R.; Ozório, R.O.A.; Shimada, M.T.; Filho, J.R.E. \& Claudiano, G.S. Efeitos benéficos de probióticos no intestino de juvenis de Tilápiado-Nilo. Pesquisa Vet Brasil, v. 33, n. 6, p. 724-730, 2013.

Piccolo, G.; Bovera, F.; Lombardi, P.; Mastellone, V.; Nizza, S.; Di Meo, C.; Marono, S. \& Nizza, A. Effect of Lactobacillus plantarum on growth performance and hematological traits of European sea bass (Dicentrarchus labrax). Aquacut Int, v. 23, n. 4, p. 1025-1032. 2015.

Pinho, S.M.; Brol, J.; Almeida, E.J.; Mello, G.L.; Jerônimo, G.T. \& Emerciano, G.C. Effect of stocking density and vertical substrate addition on growth performance and health status of fat snook Centropomus parallelus. Aquaculture, v. 457, p.73-78, 2016.

Rengpipat, S.; Rueangruklikhit, T. \& Piyatiratitivorakul, S. Evaluations of lactic acid bacteria as probiotics for juvenile sea bass Lates calcarifer. Aquac Res, v. 39, p. 134-143, 2008.

Rollo, A.; Sulpizio, R.; Nadi, M.; Silvi, S.; Orpiansei, C.; Caggiano, M.; Crec1', A. \& Carnevali, O. Live microbial feed supplement in aquaculture for improvement of stress tolerance. Fish Physiol Biochem, v. 32, p. 167-177, 2006.

Souza, R.M.; Mouriño, J.L.P.; Vieira, F.N.; Buglione, C.C.; Andreatta, E.R.; Seiffert, W.Q. \& Cerqueira, V.R. Seleção de bactérias com potencial probiótico e utilização no cultivo de robalo-peva (Centropomus parallelus). Bol. Inst. Pesca, v.36, n.1, p. 17-24, 2010.

Taoka, Y.; Maeda, H.; Jo, J. A.; Jeon, M.J.; Bai, S.C.; Lee, W.J.; Yuge, K. \& Koshio, S. Growth, stress tolerance and non-specific immune response of japonese flounder Paralichtys olivaceus to probiotics in a closed recirculating system. Fisheries Sci, v. 72, n. 2, p. 310-321, 2006.

Vega-Orellana, M.O.; Fracalossi, D.M. \& Sugai, J.K. Dourado (Salminus brasiliensis) larviculture: Weaning and ontogenetic development of digestive proteinases. Aquaculture, v. 252, p. 484-493, 2006.

Whittamore, J.M. Osmoregulation and epithelial water transport: lessons from the intestine of marine teleost fish. J Comp Physiol B, v. 182, p. 1-39, 2012.

Zar, J.H. Biostatistical analyses. Prentice Hall, $3^{\text {a }}$ ed. 662 p., Upper Saddle River, 1996. 